\title{
ANTECEDENTS AND CONSEQUENTS OF PROSPERITY AT WORK: A MEDIATION- -MODERATION MODEL
}

\author{
VLADIMIR P. NOVAES \\ (D) https://orcid.org/0000-0002-1337-2749 \\ MARIA C. FERREIRA 2 \\ (iD) https://orcid.org/0000-0003-0752-6710 \\ HELENIDES MENDONCุA \\ (iD) https://orcid.org/0000-0003-3990-5432 \\ CLÁUDIO V. TORRES ${ }^{4}$ \\ http://orcid.org/0000-0002-3727-7391
}

To cite this paper: Novaes, V. P., Ferreira, M. C., Mendonça, H., \& Torres, C. V. (2020). Antecedents and consequents of prosperity at work: A mediation-moderation model. Revista de Administração Mackenzie, 21 (1), 1-28. doi:10.1590/1678-6971/eRAM200107

Submission: June 1, 2019. Acceptance: Sept. 20, 2019.

1 Centro Universitário Universus Veritas (Univeritas), Rio de Janeiro, RJ, Brazil.

2 Universidade Salgado de Oliveira (Universo), Niterói, RJ, Brazil.

3 Pontifícia Universidade Católica de Goiás (PUC Goiás), Goiânia, GO, Brazil.

4 Universidade de Brasília (UnB), Brasília, DF, Brazil.

\section{(cc) BY




\section{ABSTRACT}

Purpose: To investigate the relationship between participation in decision making and social support at work with role performance at work, as well as the mediator role of work prosperity and the moderator role of self-efficacy.

Originality/value: The study contributes to the enhancement of the monological net of the concept of prosperity at work, by testing a model that includes other rather neglected constructs as antecedents and consequents of prosperity at work, and by analyzing the role of a personal asset in these relationships, based on the demands-resources model (JD-R).

Design/methodology/approach: This is an empirical study, with a quantitative approach of correlational nature, that tested seven hypotheses. The data were collected with self-report questionnaires, and analyzed with structural equation modelling.

Findings: All hypotheses were corroborated and indicated that: participation in the decision making and social support have a positive impact on prosperity at work; prosperity at work has a mediation role in the relation between these variables and role performance at work; self-efficacy moderates the positive relations of participation at work and social support with prosperity at work, increasing these relations. The study has important implications for the literature in the field, contributing to the application of the model of prosperity at work to Brazilian samples. Organizations may benefit from these findings if the policies that enhance prosperity are implemented in the organizational environment, obtaining competitive advantage.

\section{KEYWORDS}

Prosperity at work. Self-efficacy. Participation in the decision making. Social support. Performance at work. 


\section{INTRODUCTION}

Currently, organizations have been operating in an environment of continuous economic and technological change and experiencing strong competitive pressure in the world market, leading them to continually adjust to such scenarios (Cummings \& Worley, 2014). These adaptations have direct implications on employee's well-being.

Labor welfare scholars have, over time, adopted different constructs as manifestations of such a phenomenon, such as job satisfaction, flourishing at work, positive and negative affects on the work context, and thriving at work (Fisher, 2014). Of particular interest for the present investigation is thriving at work, which consists of a psychological state composed of the combined experience of vitality and learning in the workplace (Spreitzer, Sutcliffe, Dutton, Sonenshein, \& Grant, 2005). According to Spreitzer et al. (2005), the resources arising from work and the contextual factors of the work environment are key mechanisms for the fostering of thriving at work and, consequently, work performance.

However, such a model needs further empirical verification, as it is relatively new, which has been appointed as the reason why research on the antecedents and consequents of thriving at work is still quite scarce (Niessen, Sonnentag, \& Sach, 2012). Based on these considerations, the present study empirically tested a model that encompasses both contextual factors (participation in decision making), and resources produced by work (social support) as antecedents of thriving at work, as well as a consequence of such a construct: the performance of work roles.

The study also aimed to analyze the moderating role of a personal resource, self-efficacy, in the relationships between participation in decision making, social support and thriving at work. Such moderation is justified by the assumptions of the theory of job demands-resources (JD-R) (Bakker \& Demerouti, 2007) that, according to which personal resources can act as moderators of the relationship between labor resources and demands, and occupational well-being (Novaes, Ferreira, \& Valentini, 2018; Tremblay \& Messervey, 2011).

The research, therefore, has important implications for the literature and practice. Thus, it contributes to the extension of the proposal by Spreitzer et al. (2005), by testing a model that jointly encompasses poorly studied constructs, such as antecedents and consequents of thriving at work, and analyzes the role of a personal resource in these relationships, based on the theory of JD-R. In addition, organizations will be able to benefit from 
these findings and gain competitive advantage by implementing measures capable of enhancing thriving in the organizational environment.

\section{THEORETICAL GROUNDING}

\subsection{Participation in decision making, social support, and thriving at work}

Thriving at work has been defined as a joint experience of vitality and learning in the workplace (Spreitzer et al., 2005). Vitality refers to the subjective experience of energy and liveliness, while learning refers to the feeling one experiences in acquiring and applying knowledge and skills at work.

This construct has been approached through the model proposed by Spreitzer et al. (2005) that, according to which, the contextual factors and the resources resulting from work are characterized as antecedents of thriving at work. Contextual factors refer to work settings that encourage decision making (the degree to which the individual is allowed to make decisions that affect his or her own work), information sharing (the extent to which information is widely communicated throughout the unit) and the climate of trust and respect among different work teams (Spreitzer et al., 2005). Such contextual factors of the work environment contribute to an increased thriving at work by stimulating personal growth, learning and development (Demerouti, Bakker, Nachreiner, \& Schaufeli, 2001; Schaufeli \& Taris, 2014), i.e., to have extrinsic motivational potential.

In the present study, participation in decision-making was adopted as a contextual factor, which refers to the fact that the individual exerts influence on the decision-making processes inherent to the work environment, such as deliberations about work design and discussions about problems, in connection with working with senior managers (Podsakoff, MacKenzie, Paine, \& Bachrach, 2000). Studies have shown that the mere belief in the ability to influence the environment tends to reduce stress; in addition, effective participation in decision-making allows workers to remove obstacles that hinder effective performance and focus on their work, which tends to lead to increased levels of job satisfaction (Afrasiabi, Solokloo, \& Ghodrati, 2013) and job engagement (Hu, Schaufeli, \& Taris, 2016; Schaufeli \& Taris, 2014). Other investigations suggest that when employees are encouraged to participate in more initiatives that imply growth and learning opportunities, they tend to thrive (Spreitzer, Porath, \& Gibson, 2012). 
At the end of our literature review, and taking into account the databases searched (SciELO, PsycINFO), only one study was found that investigated the direct influence of participation in decision making on thriving at work (Sia \& Duari, 2018), having found positive effects of participation in decision making on thriving at work. Thus, a working environment that encourages individuals to make decisions that affect their own job is likely to foster greater thriving at work. In this connection, Spreitzer et al. (2005) propose that work contexts that stimulate decision-making, by giving individuals greater freedom of choice about how to do their job, tend to strengthen feelings of autonomy, which ultimately lead to greater thriving at work. In this connection, the following hypothesis was formulated:

- H1: Participation in decision making is positively associated with thriving at work.

The resources produced in carrying out the work, which, in turn, refer to access to information (understanding of work practices and how they are performed); perception of task significance (purpose and meaning inherent to work, arising from the formation of values related to work, colleagues and/or the organization), positive affect towards work (positive feelings and emotions experienced in the workplace, such as joy, contentment and gratitude); and the degree of relationship with colleagues (bond created in the workplace between individuals on the same team or from different sectors of the organization), according to Spreitzer et al. (2005), these resources are produced during work performance.

In the present investigation, social support in the work environment was approached as a resource produced in the accomplishment of the work; it consists of the emotional and/or instrumental help that the individual receives from the people that integrate the social networks of his/her daily work (Gomide Jr., Guimarães, \& Damásio, 2004). Empirical studies have shown that the perception of social support in the workplace promotes job well-being and job satisfaction (Hombrados-Mendieta \& Cosano-Rivas, 2013), as well as job performance (AbuAlRub, 2004), and decreases the likelihood of burnout and intention to leave the job (Nissly, Mor Barak, \& Levin, 2005).

Therefore, employees who enjoy more emotional support from their co-workers and supervisors would be expected to experience higher levels of thriving at work. In this regard, Spreitzer et al. (2005) argue that individuals who continually receive support from their co-workers and supervisors, experiencing a high degree of connectivity with them, tend to exhibit higher levels of thriving at work. Moreover, according to the theory of social learning 
(Bandura, 1977), employees who take care of each other in the workplace strive to ensure better working methods and produce better learning and knowledge indices due to the positive interactions they develop (Paterson, Luthans, \& Jeung, 2014). They also experience higher levels of vitality in the workplace. Thus, the following hypothesis was formulated:

- H2: Social support at work is positively associated with thriving at work.

\subsection{Thriving at work and work role performance}

The model by Spreitzer et al. (2005) considers that thriving at work is characterized as being a type of subjective meter that individuals use to discern whether or not they have control over their own development at work. It can, therefore, be seen as an indicator of the fact that the individual is developing in a positive direction, that is, seeking conditions that stimulate the individual's growth. So, when people thrive, they also achieve better job performance.

In the present study, job performance was operationalized by work role performance, which concerns the set of responsibilities regarding one's own performance (Griffin, Neal, \& Parker, 2007; Murphy \& Jackson, 1999). This variable has been shown to be a positive consequence of organizational commitment (Griffin et al., 2007), work redesign behaviors (Demerouti, Bakker, \& Halbesleben, 2015) and work recovery (Volman, Bakker, \& Xanthopoulou, 2013). Therefore, role playing could also act as a positive consequence of thriving at work. Based on the assumption that individuals who experience feelings of vitality and learning in the workplace tend to develop a high degree of job performance (Spreitzer et al., 2005), given that thriving at work makes employees more interested in their development and growth, a positive relationship between thriving and job roles should be expected.

Results in this direction have been obtained from research that indicates that thriving at work predicts individual job performance beyond attitudinal variables such as job satisfaction and organizational commitment (Porath, Spreitzer, Gibson, \& Garnett, 2012; Spreitzer et al., 2012). Based on these arguments and findings, the following hypothesis was formulated:

- H3: Thriving at work is positively associated with job performance.

\subsection{The mediation of thriving at work}

The model by Spreitzer et al. (2005) also predicts an indirect relationship between labor resources and contextual factors in the workplace and work 
performance, mediated by thriving at work. In other words, the authors argue that work-related resources and contextual factors are key mechanisms for promoting thriving at work, which, in turn, lead to greater employees' growth, better mental health, and improved job performance. In summary, both contextual factors and work-related resources lead individuals to experience higher levels of thriving at work and, consequently, better work performance.

Congruent with this model, empirical studies have indicated that thriving at work mediated the relationship between work connectivity and work innovation (Carmeli \& Spreitzer, 2009), as well as the organization's perceived support for work behavior innovation and turnover intention (Abid, Zahra, \& Ahmed, 2016). In the present study, as pointed out earlier, labor performance was made operational by the role performance at work. Hence, we investigated the mediating role of thriving at work in the relationships of participation in decision making and social support with the performance of roles at work.

Based on Spreitzer et al. (2005) formulations, it is possible that individuals who have greater incentives and encouragement to participate in decision-making may eventually become involved in decisions that affect their work, leading them to experience more positive feelings of vitality, effectiveness and ability at work, which will facilitate their job learning and help them to develop in a more positive direction at work, that is, towards greater work role performance. In this connection, the following hypothesis was formulated:

- H4: Thriving at work mediates the positive relationship between decision-making participation and job role play.

Similarly, individuals who enjoy a social context in which they interact satisfactorily with their supervisors and co-workers are expected to perceive the problems they encounter along the way as being positive challenges, and thus feel more energetic and with vitality to pursue innovative solutions through continuous learning, which, in turn, would result in an improved job performance. Thus, the hypothesis below was set:

- H5: Thriving at work mediates the positive relationship between social support at work and job role play.

\subsection{The moderating role of self-efficacy at work}

From the perspective of the theory of JD-R (Bakker \& Demerouti, 2007), both contextual factors and labor resources are designated as labor resources, 
and are characterized as physical, social or organizational aspects that are functional to achieve work goals, as they reduce the demands and the associated psychological and physical costs (Xanthopoulou, Bakker, Demerouti, \& Schaufeli, 2007). Still, according to this theory, personal resources can act as moderators of the relations between labor demands and resources and labor well-being (Schaufeli \& Bakker, 2004). Such personal resources refer to the psychological capabilities that serve as the basis for easier adaptation to life's changes and circumstances (Hobfoll, 2002). It is therefore postulated that individuals with higher levels of personal resources have greater mastery of their lives, which helps them cope more effectively with the demands of work in order to lessen the negative impact of demands and maximize the positive impact of workers' resources on labor well-being (Novaes et al., 2018).

Consistent with these assertions, personal resources such as optimism, self-esteem, satisfaction with compassion, psychological flexibility, and selfefficacy have been found to moderate the relationships between the job demands (such as work overload, insecurity and functions overload) and labor well-being, as well as the relationships between labor resources (such as autonomy, social support, and training) and well-being at work (Novaes et al., 2018; Tremblay \& Messervey, 2011). However, the role played by personal resources in the relationship between labor resources and their consequences still needs further clarification (Airila et al., 2014).

Based on these considerations, the present investigation tested the moderating role of self-efficacy (personal resource) in the relationships of participation in decision making (resource of work of a contextual nature) and social support (resource arising from work) with thriving at work. Self-efficacy concerns individuals' beliefs about their ability to successfully complete a particular course of action (Bandura, 1977), i.e., individuals' perceptions of their skills and beliefs for the purpose of succeeding in work tasks. Empirical studies have shown that self-efficacy at work has acted as a moderator of the relationships between work conditions and levels of occupational stress (Tucker, Jimmieson, \& Oei, 2013), as well as the impacts of stressful situations on engagement (Ouweneel, Schaufeli, \& Le Blanc, 2013).

It is expected that individuals who believe in their ability to perform their work tasks will be more motivated to achieve their work goals, which will lead to the potential impact of factors in the work context (participation in decision making) and labor resources (social support) on thriving. Thus, the following hypotheses were formulated: 
- H6: Self-efficacy at work moderates the positive relationship between participation in decision making and thriving at work.

- H7: Self-efficacy at work moderates the positive relationship between social support and thriving at work.

In Figure 2.4.1, the theoretical model is presented. Research hypotheses are also indicated.

(Figure 2.4.1)

RESEARCH TEMPLATE

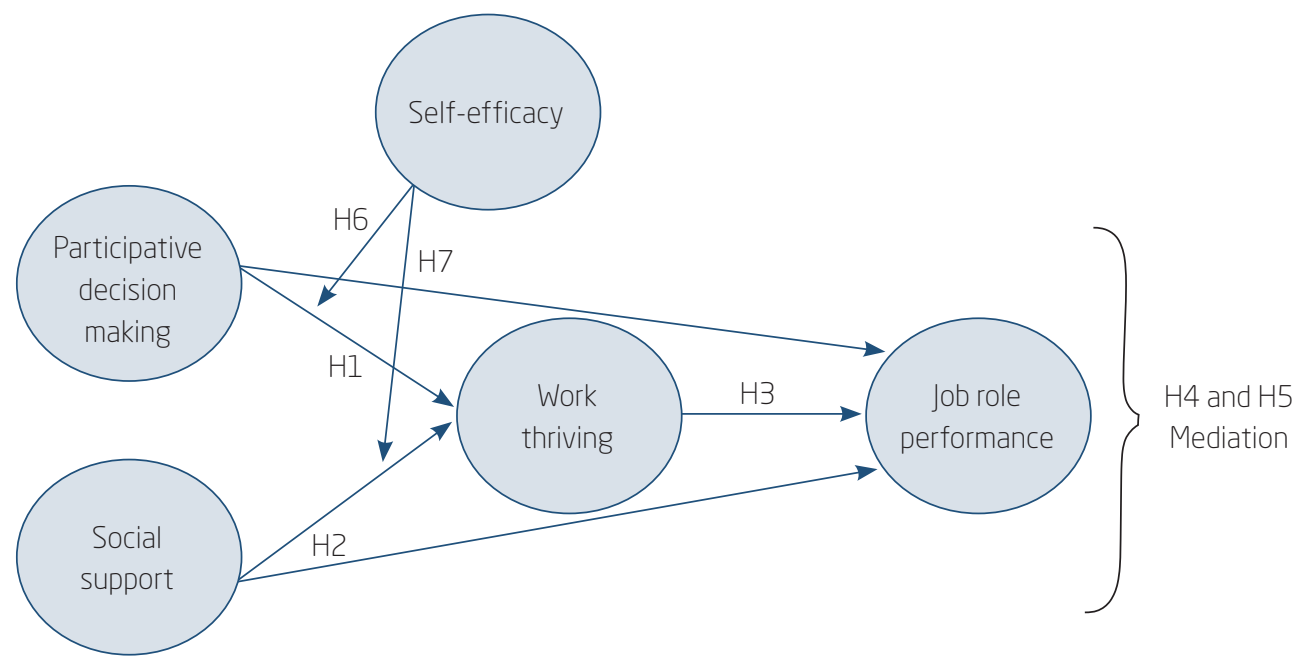

Source: Elaborated by the authors.

\section{METHOD}

\subsection{Participants and procedures}

The study was submitted to the Research Ethics Committee of the Salgado de Oliveira University, Niterói, Brazil. Data collection was performed online, with the instruments forms made available in the Google Docs platform. Individuals were contacted by email and social networks and received a link to access the questionnaire. They agreed to participate in the investigation by completing the Informed Consent Form.

The sample was selected by convenience and the only inclusion criterion for participation was that the person had worked for at least one year. It was 
made up of 595 employees from public $(31.2 \%)$ and private $(68.8 \%)$ organizations from Rio de Janeiro and Niterói, Brazil, who voluntarily agreed to participate in the survey. Most participants were female $(64.5 \%)$ and their ages ranged from 18 to 71 years old $(M=34.32$; $S D=12.27)$. Regarding education level, $37.1 \%$ had completed college and $28.4 \%$ had not completed college. Regarding marital status, $46.7 \%$ were married and $45.7 \%$ were single, and, regarding the salary range, $62 \%$ received from one to three minimum wages. The working time of participants in their current organization ranged from 1 to 30 years $(M=5.57 ; S D=7.31)$, while total working time ranged from 1 to 49 years $(M=12.35 ; S D=10.72)$. Regarding the function performed, $48 \%$ worked in administration.

\subsection{Instruments}

Social support at work was assessed by two scales of the Job Content Questionnaire (JCQ) (Karasek et al., 1998) - supervisor's social support and co-worker's social support -, adapted to the Brazilian context by Araújo and Karasek (2008). They are answered on a five-point Likert scale ranging from strongly disagree (1) to strongly agree (5) and both consist of three items. Example of a supervisor's social support item: "My direct boss often pays attention to the things I say." Example of a social support item from colleagues: "The people I work with are friendly". In the present investigation, however, social support was considered one-dimensional, by aggregating the scores on the supervisor's and the co-worker social support's scales. The confirmatory factor analysis (CFA) results for this scale presented the following adjustment indices: $\chi^{2}=23.09$ (5), RMSEA $=0.07$, CFI $=0.96$, and TLI $=0.97$. Cronbach's alpha was 0.70 .

Participation in decision making was assessed by a scale adapted by Tyler and Blader (2000), consisting of four items, to be answered on a sevenpoint Likert-like agreement scale, ranging from strongly disagree (1) to very strongly agree (7). Example of an item: "I feel able to influence the decisions made in my organization." The CFA of the scale model, of a unifactorial nature, presented the following adjustment indices: $\chi^{2}=9.10(2)$, RMSEA $=$ 0.07 , CFI $=0.99$, and TLI $=0.98$. Cronbach's alpha of the scale was 0.86 .

To assess thriving at work, the Thriving at Work Scale (Porath et al., 2012), adapted to the Brazilian context by Novaes, Ferreira, and Valentini (2015), was used; it consists of nine items, to be answered in a seven-point Likert-like scale ranging from strongly disagree (1) to strongly agree (7). The scale is subdivided into five items for learning (for example: "I am often 
learning in my work") and four for vitality (for example: "In my work I feel alive and indispensable"). Such bi-factorial scale presented in the CFA the following adjustment indices: $\chi^{2}=45.63$ (27), RMSEA $=0.03$, CFI $=0.99$ and TLI $=0.99$. The Cronbach's alphas were 0.87 for the learning factor, 0.84 for the vitality factor and 0.90 for the general factor.

To evaluate the performance of working roles, six items of the scale developed by Griffin et al. (2007), to be answered on seven-point Likert-like frequency scales, ranging from never (1) to always (7) were used. Example of an item: "I helped my co-workers when requested or when needed." In the current study, the CFA results showed the following adjustment indices: $\chi^{2}=12.21$ (9), RMSEA $=0.02$, CFI $=0.99$ and TLI $=0.99$. Cronbach's alpha was equal to 0.86 .

To measure self-efficacy at work, we used the shortened Brazilian version of the Occupational Self-Efficacy Scale (Escala de Autoeficácia Ocupacional - EAO-VR), developed by Rigotti, Schyns, and Mohr (2008) and adapted to the Brazilian setting by Damásio, Freitas, and Koller (2014). The instrument consists of six items, to be answered on a seven-point Likert-like frequency scale, ranging from totally disagree (1) to agree (5). Example of item: "I can keep calm when I'm having difficulties at work because I rely on my skills". In the present investigation, the CFA results showed the following adjustment indices: $\chi^{2}=6.26(5)$, RMSEA $=0.02$, CFI $=0.99$ and TLI $=$ 0.99. Cronbach's alpha for the self-efficacy scale in the current survey was 0.77. In the data collection, a sociodemographic questionnaire was also adopted, which included questions regarding gender, working time, education, marital status, salary range and function performed.

\subsection{Data analysis}

Data analysis was performed with the structural equation modeling, using the Mplus software and the Weighted Least Squares Means and Variance Adjusted (WLSMV) estimation method. In the verification of the measurement model, the independent and correlated six-factor model was compared with the one-factor model and the five-factor model by means of CFA.

After confirming the measurement model, the structural model was adopted to verify the relationships between the constructs studied. Based on Hayes's (2013) recommendations, the relationship between the independent variables (decision-making participation and social support) and the dependent variable (work role performance) was initially examined, and 
such relationships must be meaningful for the mediation to exist. In the second step, the mediator variable (thriving at work) was inserted in the model to verify whether the predictor variables were related to the mediator variable and whether the latter was related to the dependent variables. According to Hayes (2013), the model shall be considered a mediation model if there is a reduction in the strength of the relationship between the predictor variables and the dependent variable, with the input of the mediator variable, and if the indirect effect of the independent variable on the dependent variable is significant. When testing the indirect effect, the standard error of the indirect effect of the mediator variable on the relationship of independent variables to dependent variables was estimated using the 500-sample bootstrap resampling procedure.

After testing the mediation model, the moderation of self-efficacy in the relationship between participation in decision making and social support with the mediator variable (thriving at work) was tested by latent interaction with the orthogonalization of items proposed by Little, Bovaird, and Widaman (2006), using the Mplus program. According to the modeling proposed by these authors, the latent interaction variables were estimated through the following steps: creation of interactions between the moderation variable and the independent variables items; orthogonalization of items based on linear regression residues; estimation of the latent variable through orthogonalized items. This procedure avoids collinearity between item interactions and allows the estimation of a latent interaction. Moreover, the parameterization of this model is simpler, which facilitates the identification of complex models with different latent variables. The following adjustment indices were analyzed: chi-square $\left(\chi^{2}-\right.$ tests the probability of the theoretical model to fit the data in which, the higher the value of $\chi^{2}$, the worse the fit); Root Mean Square Error of Approximation - RMSEA (must be less than 0.08, accepting values up to 0.10); Tucker-Lewis Index and Comparative Fit Index - TLI and CFI (should be greater than 0.90, preferably 0.95) (Brown, 2015).

\section{RESULTS}

\subsection{Measure model}

Initially, the descriptive statistics of the scales, as well as the correlations (Spearman's $\rho$ ) between the study variables (Figure 4.1.1) were calculated. 
The complete measurement model, composed by the six latent variables (participation in decision making, social support, learning, vitality, work role performance and self-efficacy), was compared with the single factor model, and with the five independent factors model (participation in decision making, social support, thriving at work, job roles performance and selfefficacy). The six latent variables model was the one that best fit the data, exhibiting the following adjustment indices: $\chi^{2}(\mathrm{gl})=870.46$ (362); CFI $=$ 0.96 ; TLI $=0.95$; RMSEA $=0.05$. Figure 4.1.1 indicates the fit indices of the three models tested.

\section{(Figure 4.1.1)}

MEANS, STANDARD DEVIATIONS AND CORRELATIONS BETWEEN VARIABLES

\begin{tabular}{llccccccccc}
\hline & Mean & SD & 1 & 2 & 3 & 4 & 5 & 6 \\
\hline 1 & Vitality & 5.20 & 1.16 & $(0.84)$ & - & - & - & - & - \\
\hline 2 & Learning & 5.69 & 1.20 & 0.71 & $(0.87)$ & - & - & - & - \\
\hline 3 & Participation in decision making & 4.43 & 1.33 & 0.25 & 0.21 & $(0.86)$ & - & - & - \\
\hline 4 & Social support & 3.83 & 0.78 & 0.38 & 0.30 & 0.37 & $(0.70)$ & - & - \\
\hline 5 & Work role performance & 5.96 & 0.93 & 0.47 & 0.37 & 0.27 & 0.30 & $(0.86)$ & - \\
\hline 6 & Self-efficacy & 4.14 & 0.67 & 0.33 & 0.21 & 0.39 & 0.22 & 0.42 & $(0.77)$ \\
\hline
\end{tabular}

All correlations were significant at $p<0,01$ level. Note: The main diagonal presents the reliability coefficients (Cronbach's alpha) of the instruments.

(Figure 4.1.2)

ADJUSTMENT INDICES OF TESTED MODELS

\begin{tabular}{lcccc}
\multicolumn{1}{c}{ Models } & $\chi^{2}(\mathrm{gl})$ & CFI & TLI & RMSEA (CI) \\
\hline Model with six correlated factors & $870.46(362)$ & 0.96 & 0.95 & $0.049(0.045-0.053$ \\
\hline One-factor model & $2,608.82(377)$ & 0.81 & 0.80 & $0.100(0.096-0.103)$ \\
\hline Five-factor model & $923.14(367)$ & 0.95 & 0.94 & $0.051(0.046-0.055)$ \\
\hline
\end{tabular}

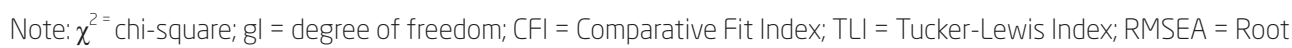
Mean Square Error of Approximation; $\mathrm{Cl}=$ confidence interval. 


\subsection{Hypothesis test}

Initially, the direct effects of participative decision-making (PDM) and social support (SS) on the two factors of thriving at work (vitality $-\mathrm{V}$ and learning $-\mathrm{L}$ ) were verified. Results indicated that these effects were significant (PDM/A: $\beta=0.32, p<0.001, \mathrm{CI}(95 \%)=0.36-0.27$; PM/V: $\beta=0.25, p<0.001, \mathrm{CI}(95 \%)=0.30-0.21$; SS $/ \mathrm{A}: \beta=0.59, p<0.001$, $\mathrm{CI}(95 \%)=0.63-0.54$; SS $/ \mathrm{V}: \beta=0.62, p<0.001, \mathrm{CI}(95 \%)=0.66-0.57)$, which confirmed hypotheses 1 and 2 . The relationships between the two factors of the mediating variable (thriving at work) and the dependent variable (work role performance - WRP) were also positive and significant (A and WRP: $\beta=0.28, p<0.001$; V and WRP: $\beta=0.52, p<0.001$ ), which also supported hypothesis 3 of the present study.

In order to verify the mediating role of thriving at work, the direct effects of PDM and SS on WRP were initially tested. Results indicated that such effects were significant (PDM/WRP: $\beta=0.14, p<0.001$, CI $(95 \%)=0.18$ 0.10 ; SS/WRP: $\beta=0.47, p<0.001, \mathrm{CI}(95 \%)=0.52-0.42)$. The inclusion of the two factors of thriving at work $(\mathrm{V}$ and $\mathrm{L})$ as a mediator variable in the model pointed out that, in addition to the direct effects, the indirect effects of the relationships between PDM, thriving at work and WRP were statistically significant (PDM-L-WRP: $\beta=0.11, p<0.001, \mathrm{CI}(95 \%)=0.17$ 0.06; PDM-V-WRP: $\beta=0.13, p<0.001$, CI(95\%) $=0.19-0.08)$, as well as the relationships between social support, thriving at work, and work role performance (SS-A-WRP: $\beta=0.37, p<0.001$, CI $(95 \%)=0.43-0.31$; SS-VWRP: $\beta=0.32, p<0.001, \mathrm{CI}(95 \%)=0.38-0.27)$. In short, thriving at work mediated the relationship between PDM and WRP, as well as SS at work with WRP, which allowed supporting hypotheses 4 and 5.

Regarding the interaction between PDM and self-efficacy in predicting thriving at work, it was observed that self-efficacy moderated the positive relationships with the two factors of thriving at work (V and $\mathrm{L}$ ), enhancing them. Thus, it was found that the individual with low self-efficacy (SE-PDM-V: $\beta=0.06$, ns; SE-PDM-L: $\beta=0.07$, ns) exhibited a non-significant relationship between participative decision making and thriving factors, whereas when self-efficacy was high (SE-PDM-V: $\beta=0.11 p<0.001, \mathrm{CI}(95 \%)=0.15-0.07$; SE-PDM-L: $\beta=0.14, p<0.001$, CI $(95 \%)=0.19-0.08)$, the relationships between PDM and thriving at work were positive and significant. Thus, these relationships were stronger among individuals with higher levels of self-efficacy (figures 4.2.1 and 4.2.2). These findings corroborated hypothesis 6. 
(Figure 4.2.1)

SELF-EFFICACY AS A MODERATOR OF THE RELATIONSHIP BETWEEN PARTICIPATIVE DECISION-MAKING AND VITALITY

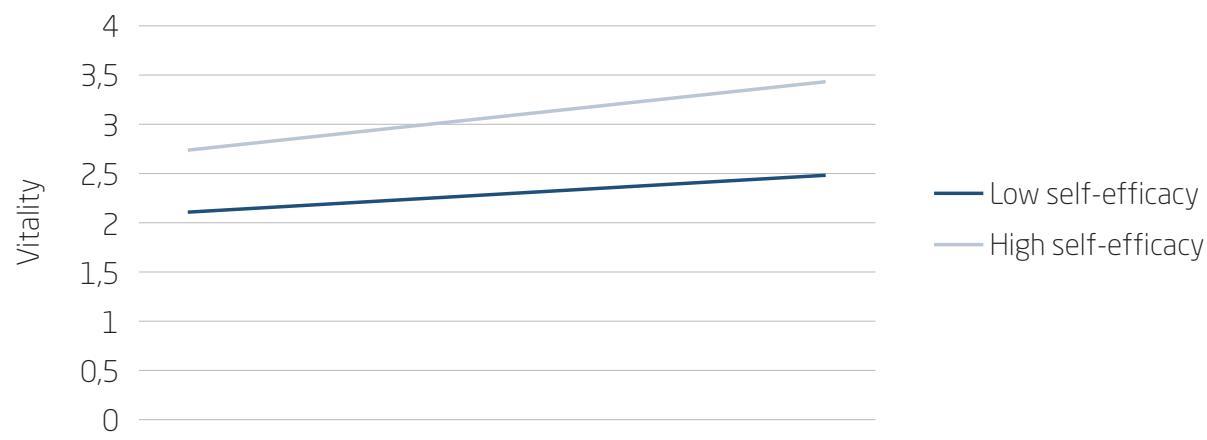

Low participation in decision making High participation in decision making

Source: Elaborated by the authors.

(Figure 4.2.2)

SELF-EFFICACY AS A MODERATOR OF THE RELATIONSHIP BETWEEN PARTICIPATIVE DECISION MAKING AND LEARNING

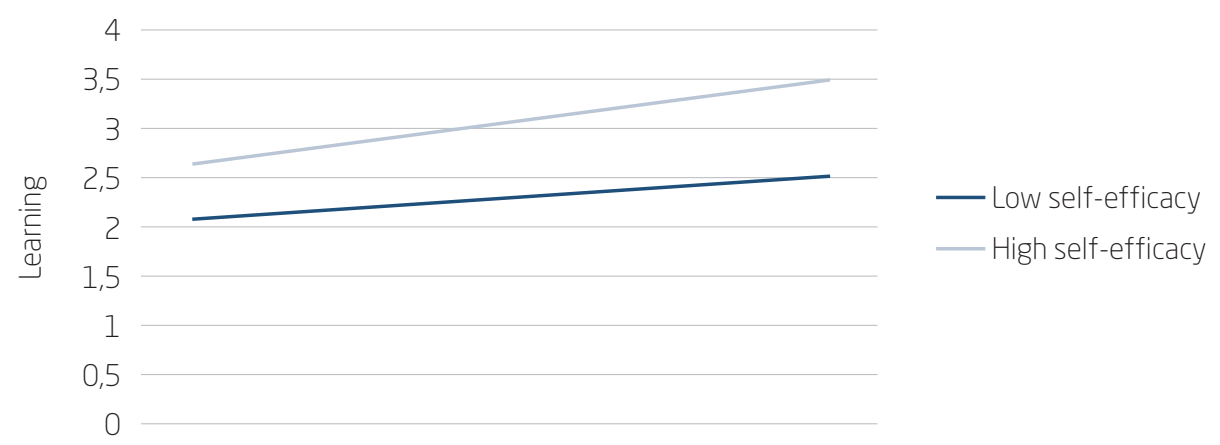

Low participation in decision making High participation in decision making

Source: Elaborated by the authors.

Finally, regarding the effects of the interaction between self-efficacy and SS on thriving at work, self-efficacy also moderated the positive relationships of social support with the two factors of thriving at work ( $\mathrm{V}$ and $\mathrm{L}$ ), in the sense of enhancing them. Thus, it was found that, in the individual with low self-efficacy (SE-SS-V: $\beta=0.08$, ns; SE-SS-L: $\beta=0.09$, ns), the relationship 
between social support and thriving factors were not significant, while when self-efficacy was high (SE-SS-V: $\beta=0.24, p<0.001, \mathrm{CI}(95 \%)=0.27-0.21$; SE-SS-L: $\beta=0.22, p<0.001, \mathrm{CI}(95 \%)=0.26-0.18)$, the relationship between SS and thriving at work were positive and significant. Thus, it was found that, among individuals with higher levels of self-efficacy, these relationships were stronger, which confirmed hypothesis 7 of the present study (figures 4.2.3 and 4.2.4). Figure 4.2.5 shows the final moderate mediation model with its relevant non-standard parameters. Finally, considering the fact that the study was correlational in nature, the inverse relationships were also tested, but the results were much lower than those previously reported, with the following adjustment indices: $\chi^{2}(\mathrm{gl})=1,283.72$ (381); CFI $=0.84$; $\mathrm{TLI}=0.86$; $\mathrm{RMSEA}=0.098$.

\section{(Figure 4.2.3)}

SELF-EFFICACY AS A MODERATOR OF THE RELATIONSHIP BETWEEN SOCIAL SUPPORT AND VITALITY

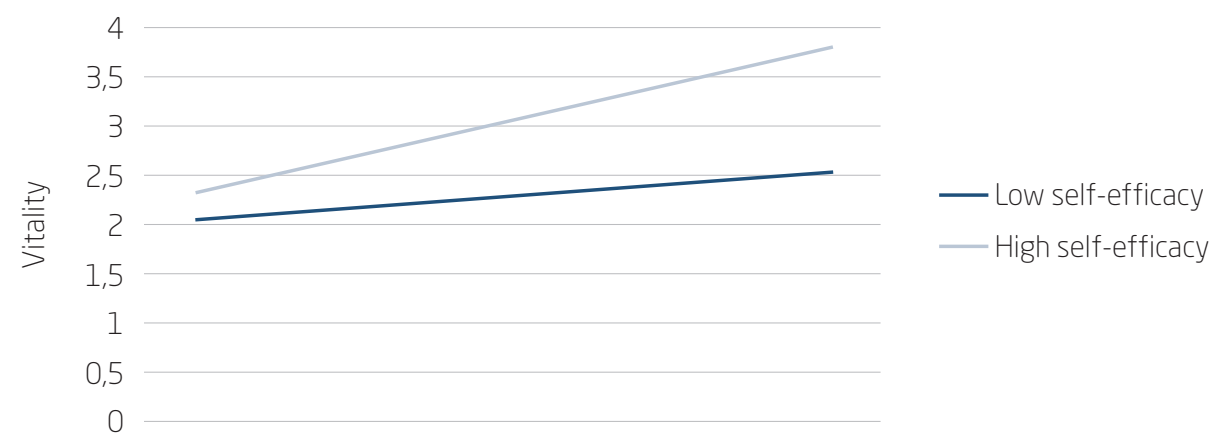

Low social support High social support

Source: Elaborated by the authors. 


\section{(Figure 4.2.4)}

\section{SELF-EFFICACY AS A MODERATOR OF THE RELATIONSHIP BETWEEN SOCIAL SUPPORT AND LEARNING}

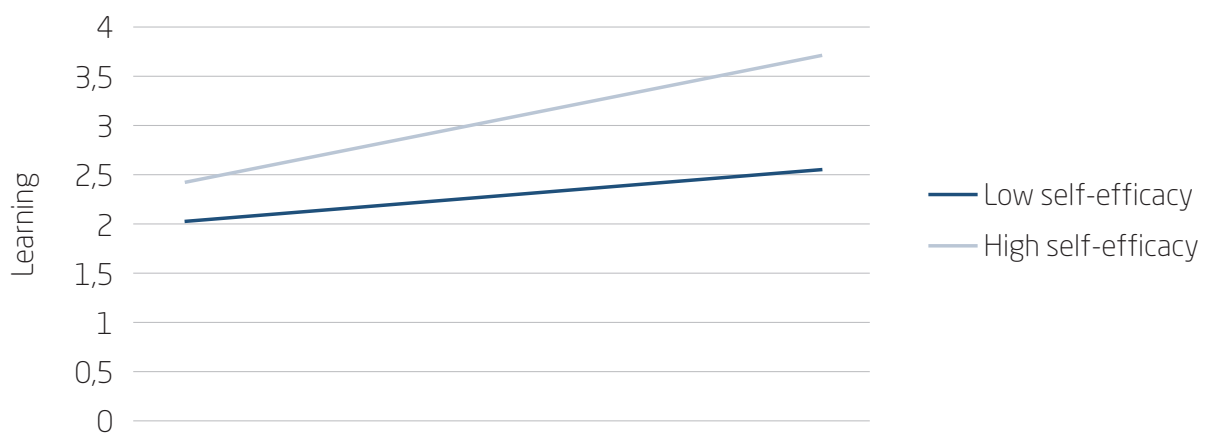

Low social support High social support

Source: Elaborated by the authors.

\section{(Figure 4.2.5)}

GRAPHICAL REPRESENTATION OF THE MODEL TESTED WITH NON-STANDARD PARAMETERS

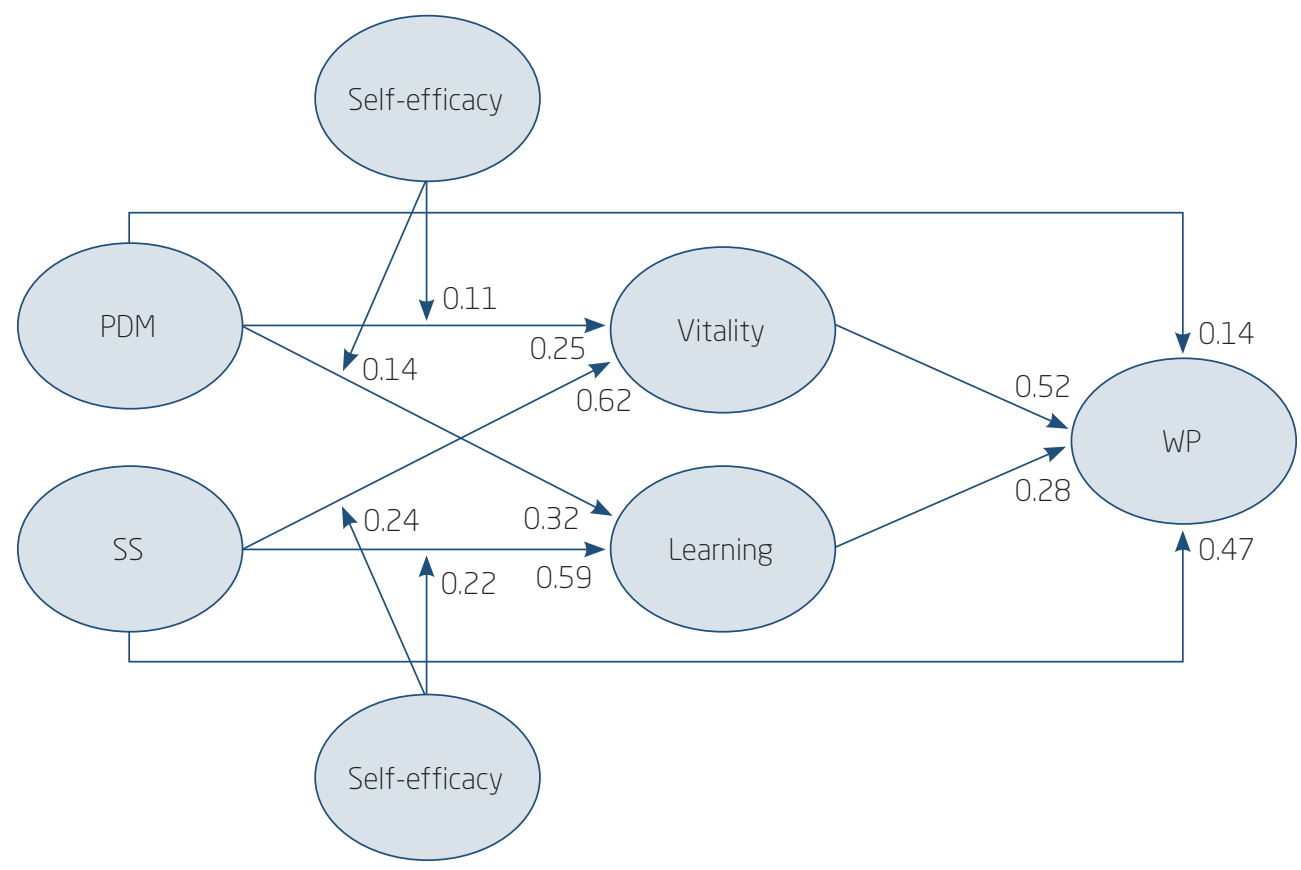

Source: Elaborated by the authors. 


\section{DISCUSSION}

The aim of the present study was to investigate the relationship of participation in decision making and social support at work with thriving at work, as well as the role of mediating thriving at work and moderating self-efficacy in such relationships. The results showed that participation in decision making indicated positive associations with the two factors of thriving at work (vitality and learning). These findings, thus, corroborated hypothesis 1 , which predicted a positive impact of participative decisionmaking on thriving at work. These results are in the direction of a previous study that demonstrated the positive effects of participative decision making on thriving at work (Sia \& Duari, 2018).

According to the model of Spreitzer et al. (2005), contextual factors, such as participation in decision making, are characterized as triggers of thriving at work. In this sense, organizations that give their employees greater freedom to make their own decisions and implement their ideas at work contribute to increasing their motivating energy at work, which leads them to explore and learn new skills (Sia \& Duari, 2018). Therefore, this finding provides empirical support for that theory, as it was found that participation in decision making acted as a factor in the labor context that positively impacts thriving at work.

Hypothesis 2 predicted that social support at work would be positively related to thriving at work, and it was also supported. This result is in agreement with the data obtained in another study (Hombrados-Mendieta \& Cosano-Rivas, 2013), in which it was observed that social support positively predicts labor well-being. Such result also provides support to the model of Spreitzer et al. (2005), and to the social learning theory (Bandura, 1977) that, according to which, social support at work tends to positively impact thriving at work. Hence, employees who enjoy the most support from their co-workers and supervisors, tend to experience greater connectivity with them and consequently have greater levels of vitality and energy in their workplace, as well as better learning and knowledge indices, i.e., they thrive at work (Feeney \& Collins, 2015).

The results obtained also showed that thriving at work was positively related to work role performance, corroborating hypothesis 3. This finding is in line with other studies that also show that thriving at work tends to predict job performance (Porath et al., 2012; Spreitzer et al., 2012). According to Spreitzer et al. (2005), thriving at work is a positive indicator of work 
performance. In this connection, individuals who experience better levels of liveliness and energy at work, in addition to being in a constant learning condition, feel more energized to seek better conditions that can stimulate their growth and development in the workplace, which ends up yielding better performance levels (Gerbasi, Porath, Parker, Spreitzer, \& Cross, 2015).

The study also showed that thriving at work mediated the relationship between participation in decision making (context resources) and social support (resources from work) with work performance, supporting hypotheses 4 and 5. In a congruent way with these findings, other empirical studies have also indicated the indirect relationship of work-related resources and contextual factors of the work environment with work performance (Abid et al., 2016; Carmeli \& Spreitzer, 2009), which mediates thriving at work. These results indicate that individuals who participate in decisionmaking and have social support from their colleagues and supervisors, that is, who are involved in decisions that directly affect their work and enjoy a working context in which they interact satisfactorily with their supervisors and their co-workers tend to engage in more focused and energetic work activities, leading them to explore new ways of doing things and to perform more earnestly in their activities (Paterson et al., 2014).

It was also observed that self-efficacy moderated the relationships of participative decision-making with thriving at work, which provided empirical support for hypothesis 6 . Thus, it was evident that higher levels of self-efficacy tend to enhance the positive relationships of participative decision-making with thriving at work. In other words, among individuals who hold higher beliefs about their skills and work performance, the impact of positive events such as participative decision-making about thriving at work tends to be enhanced. It means to say that, among individuals with higher levels of self-efficacy, the impact of participative decision making on vitality and learning is stronger.

Finally, it was observed that self-efficacy moderated the positive association of social support with thriving at work, which confirms hypothesis 7. It was shown, therefore, that among individuals who have higher beliefs about their ability to succeed in their labor goals, the relationship of social support with thriving at work is enhanced. In other words, when individuals have higher levels of self-efficacy, there is a stronger positive relationship between social support and thriving at work.

Results on self-efficacy moderation converge with findings from other studies (Novaes et al., 2018; Tremblay \& Messervey, 2011), where personal resources also acted as a moderator of the relationship between labor 
resources and labor well-being. In addition, they contribute with empirical evidence in support of the JD-R theory that (Bakker \& Demerouti, 2007), according to which, personal resources tend to act as moderators of the relationship between labor resources and labor well-being. Taken together, the results obtained at this point led to the following conclusions: participative decision making and social support have a positive impact on thriving at work; thriving at work mediates the relationship between such variables and work role performance; self-efficacy moderates the positive relationships of participative decision-making and social support with thriving at work.

Finally, it is noteworthy that, in the present investigation, the hypothesis of moderation of self-efficacy in the relationship between resources and work role performance was not tested, considering that the theoretical model that supported the investigation (Spreitzer et al., 2005) does not foresee a direct relationship between contextual factors and work-related resources with work performance. In this sense, the direct relationships subjected to testing were performed only to verify the mediation of thriving at work in these relationships, as recommended by the aforementioned model.

\section{PRACTICAL IMPLICATIONS}

The results of the present investigation allow the development of suggestions and strategies that can be implemented, aiming to reinforce the thriving levels in Brazilian workers. Considering that participative decision making and social support tend to stimulate individuals and increase their levels of thriving at work and, consequently, to obtain greater job roles performance, it is necessary that organizational management policies adopt interventions aimed at driving a more active participation of their employees in decisions about their work tasks and to encourage social support provided by their leaders and co-workers. In this regard, meetings with the participation of voting employees, and workshops designed to clarify the important role played by the supervisor's social support in employee's welfare could be implemented.

Taking into account also that self-efficacy (personal resource) associated with work-related resources (social support), and with contextual factors (participative decision-making) potentiates the impact of such positive variables on thriving at work, it would be essential that managers seek to implement individual encouragement mechanisms such as, praising and giving positive performance feedback, thereby strengthening beliefs in their 
abilities and skills to successfully complete the task, as well as increasing their levels of self-efficacy at work. Training aimed at promoting self-efficacy could also be implemented. Such strategies are fundamental for the employees to present a positive state, which may be reflected in the achievement of their thriving at work and, as a consequence, their greater well-being.

\section{LIMITATIONS AND FUTURE STUDIES}

This investigation has some limitations. The first one concerns the fact that the data were collected online, without the presence of the investigators, which may have generated a bias, which is the common method bias. A second limitation is due to the use of self-report instruments, which may also raise the question of the common method bias. Given, however, that workers themselves have clearer ideas about their job responsibilities, their work context, and their positive psychological abilities, it would be difficult to obtain accurate information with any other method but self-report (Spector, 2006). Moreover, the problem of the common method bias may have been minimized for two other reasons: one is that the anonymity of the respondents was ensured, as well as the fact that there was no right or wrong answer, i.e., no risk of personal or professional harm to the respondents. The other was that the items dealt with distinct variables, as observed in the measurement model analysis, which may help to avoid biased responses (Podsakoff, MacKenzie, \& Podsakoff, 2012).

Another limitation is in connection with the cross-sectional nature of the study, which prevents causal inferences from being made between the variables. Future research can correct this limitation with the adoption of longitudinal designs, which allows for a better understanding of the relationships between the variables of the present investigation. A third limitation is related to data collection performed online, without the presence of the investigators, which may have generated a lack of commitment and less reliable responses. Thus, future research could be conducted using in-person collection process. Finally, future research using other predictive variables of thriving is also needed to better assess the mediating role of such a construct and moderator of personal resources in such relationships. Such investigations may undoubtedly contribute to the deepening of an understanding about the contextual factors and the resources produced in the job performance that interfere in thriving at work and, consequently, for the implementation of measures capable of promoting the thriving development in the organizational environment. 


\section{ANTECEDENTES E CONSEQUENTES DA PROSPERIDADE NO TRABALHO: UM MODELO DE MEDIAÇÃO MODERADA}

) RESUMO

Objetivo: Investigar as relações da participação na tomada de decisões e do suporte social no trabalho com o desempenho de papéis no trabalho, assim como o papel mediador da prosperidade no trabalho e o papel moderador da autoeficácia em tais relações.

Originalidade/valor: $O$ estudo contribuiu para a extensão da rede monológica da prosperidade no trabalho, ao testar um modelo que engloba conjuntamente construtos pouco estudados como antecedentes e consequentes da prosperidade no trabalho, além de analisar o papel de um recurso pessoal nessas relações, com base na teoria de demandas e recursos do trabalho (JD-R).

Design/metodologia/abordagem: A pesquisa é de natureza empírica, com abordagem quantitativa de natureza correlacional, e testou sete hipóteses. Os dados foram coletados por meio de questionários de autorrelato e analisados pela modelagem de equações estruturais.

Resultados: As hipóteses foram totalmente corroboradas e indicaram os seguintes aspectos: a participação na tomada de decisões e o suporte social exercem impacto positivo sobre a prosperidade no trabalho; a prosperidade no trabalho medeia a relação entre tais variáveis e o desempenho de papéis no trabalho; a autoeficácia modera as relações positivas da participação na tomada de decisões e do suporte social com a prosperidade no trabalho, no sentido de acentuá-las. A pesquisa traz importantes implicações para a literatura, ao contribuir para a extensão do modelo de prosperidade no trabalho a amostras brasileiras. As organizações poderão se beneficiar de tais achados e obter vantagem competitiva ao implantarem medidas capazes de promover melhorias no que diz respeito à prosperidade no ambiente organizacional.

\section{PALAVRAS-CHAVE}

Prosperidade no trabalho. Autoeficácia. Participação na tomada de decisão. Suporte social. Desempenho de papéis no trabalho. 


\section{REFERENCES}

Abid, G., Zahra, I., \& Ahmed, A. (2016). Promoting thriving at work and waning turnover intention: A relational perspective. Future Business Journal, 2, 127-137. doi:10.1016/j.fbj.2016.08.001

AbuAlRub, R. F. (2004). Job stress, job performance, and social support among hospital nurses. Journal of Nursing Scholarship, 36, 73-78. doi:10.1111/j.1547-5069.2004.04016.x

Afrasiabi, H., Solokloo, B. J., \& Ghodrat1, H. (2013). A study of job satisfaction in relation to participation and alienation. Journal of Applied Sociology, 49, 45-48. Retrieved from https://eur01.safelinks.protection.outlook. com/?url=http\%3A\%2F\%2Fuijs.ui.ac.ir\%2Fjas\%2Farticle1-518-en.pdf\&

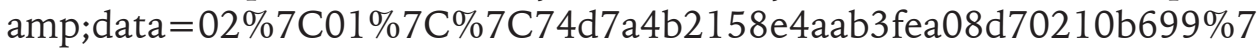
C84df9e7fe9f640afb435aaaaaaaaaaa\%7C1\%7C0\%7C636980143605279 172\&amp;sdata=oTkUzOqPgmuadGJy\%2Ftj2CnFTyFro\%2BEp7QdD9bp fmpao\%3D\&amp;reserved $=0$

Airila, A., Hakanen, J. J., Schaufeli, W. B., Luukkonen, R., Punakallio, A., \& Lusa, S. (2014). Are job and personal resources associated with work ability 10 years later? The mediating role of work engagement. Work $\mathcal{E}$ Stress, 28, 87-105. doi:10.1080/02678373.2013.872208

Araújo, T. M., \& Karasek, R. (2008). Validity and reliability of the Job Content Questionnaire in formal and informal jobs in Brazil. Scandinavian Journal of Work Environment \& Health, 34, 52-59.

Bakker, A. B., \& Demerouti, E. (2007). The job demands-resources model: State of the art. Journal of Managerial Psychology, 22, 309-328. doi:10.1108/ 02683940710733115

Bandura, A. (1977). Self-efficacy: toward a unifying theory of behavioral change. Psychological Review, 84, 191-215. Retrieved from https://eur01. safelinks.protection.outlook.com/?url=http\%3A\%2F\%2Fdx.doi.org\%2 F10.1037\%2F0033-295X.84.2.191\&amp;data $=02 \% 7 C 01 \% 7 C \% 7 C 74 d 7 a$ 4b2158e4aab3fea08d70210b699\%7C84df9e7fe9f640afb435aaaaaaaaaaaa \%7C1\%7C0\%7C636980143605279172\&amp;sdata=q\%2B\%2BxMaela8 ckeGXu2EdqCuAUyc1KNQTKxTRQmAIX\%2FJA\%3D\&amp;reserved =0

Brown, T. A. (2015). Confirmatory factor analysis for applied research. New York: The Guilford Press.

Carmeli, A., \& Spreitzer, G. M. (2009). Trust, connectivity, and thriving: Implications for innovative behaviors at work. The Journal of Creative Behavior, 43, 169-191. doi:10.1002/j.2162-6057.2009.tb01313.x 
Cummings, T. G., \& Worley, C. G. (2014). Organization development and change. Mason, OH: Thomson, South-Western.

Damásio, B. F., Freitas, C. P. P., \& Koller, S. H. (2014). Occupational SelfEfficacy Scale-Short Form (OSS-SF): Adaptation and evidence of construct validity of the Brazilian version. Revista Brasileira de Orientação Profissional, 15, 65-73. Retrieved from http://pepsic.bvsalud.org/scielo.php? script= sci_issues\&pid $=1679-3390 \& \operatorname{lng}=$ pt\&nrm $=$ iso

Demerouti, E., Bakker, A. B., \& Halbesleben, J. R. (2015). Productive and counterproductive job crafting: A daily diary study. Journal of Occupational Health Psychology, 20, 457-469. doi:10.1037/ocp0000012

Demerouti, E., Bakker, A. B., Nachreiner, F., \& Schaufeli, W. B. (2001). The job demands-resources model of burnout. Journal of Applied Psychology, 86, 499-512. doi:10.1037/0021-9010.86.3.499

Feeney, B. C., \& Collins, N. L. (2015). A new look at social support: A theoretical perspective on thriving through relationships. Personality and Social Psychology Review, 19, 113-147. doi:10.1177/1088868314544222

Fisher, C. D. (2014). Conceptualizing and measuring wellbeing at work. In P. Y. Chen \& C. L. Cooper (Eds.). Work and wellbeing (Vol. 3, pp. 9-34). New York: Wiley.

Gerbasi, A., Porath, C. L., Parker, A., Spreitzer, G., \& Cross, R. (2015). Destructive de-energizing relationships: How thriving buffers their effect on performance. Journal of Applied Psychology, 100, 1423-1433. doi:10.10 37/ap10000015

Gomide, S., Jr., Guimarães, L. C., \& Damásio, L. F. Q. (2004). Construção e validação de um instrumento de medida de percepção de suporte social no trabalho. Seminário GIBEST do Grupo de Interinstitucional de Pesquisa sobre Bem-estar, Suporte Social e Trabalho, Uberlândia, MG, Brasil, 2.

Griffin, M. A., Neal, A., \& Parker, S. K. (2007). A new model of work role performance: Positive behavior in uncertain and interdependent contexts. Academy of Management Journal, 50, 327-347. doi:10.5465/amj.2007.246 34438

Hayes, A. F. (2013). Introduction to mediation, moderation, and conditional process analysis. New York: Guilford.

Hobfoll, S. E. (2002). Social and psychological resources and adaptation. Review of General Psychology, 6, 307-324. Retrieved from https://eur01. safelinks.protection.outlook.com/? url=https\%3A\%2F\%2Fdoi.org\%2 F10.1037\%2F1089-2680.6.4.307\&amp;data =02\%7C01\%7C\%7C74d7a4 b2158e4aab3fea08d70210b699\%7C84df9e7fe9f640afb435aaaaaaaaaaa\% 7C1\%7C0\%7C636980143605289189\&amp;sdata=sk2E7Tsby3YBwrt\% 2F5L6TgpmzGTm0fzGyjP0Eckqr2Xo\%3D\&amp;reserved =0 
Hombrados-Mendieta, I., \& Cosano-Rivas, F. (2013). Burnout, workplace support, job satisfaction and life satisfaction among social workers in Spain: A structural equation model. International Social Work, 56, 228-246. doi: $10.1177 / 0020872811421620$

Hu, Q., Schaufeli, W. B., \& Taris, T. W. (2016). Extending the job demandsresources model with guanxi exchange. Journal of Managerial Psychology, 31, 127-140. doi:10.1108/JMP-04-2013-0102

Karasek, R., Brisson, C., Kawakami, N., Houtman, I., Bongers, P., \& Amick, B. (1998). The Job Content Questionnaire (JCQ): An instrument for internationally comparative assessments of psychosocial job characteristics. Journal of Occupational Health Psychology, 3, 322-355. Retrieved from https:// eur01.safelinks.protection.outlook.com/? url=https\%3A\%2F\%2Fdoi. org\%2F10.1111\%2Fj.1744-6570.2010.01175.x\&amp;data=02\%7C01\%7C \%7C74d7a4b2158e4aab3fea08d70210b699\%7C84df9e7fe9f640afb435 aaaaaaaaaaa\%7C1\%7C0\%7C636980143605289189\&amp;sdata =uPJL 2hbSgwHbOB7ruaNxTCnBUbrWuA\%2B8osPRO\%2BA9Ljg\%3D\&amp; reserved $=0$

Little, T. D., Bovaird, J. A., \& Widaman, K. F. (2006). On the merits of orthogonalizing powered and product terms: Implications for modeling interactions among latent variables. Structural Equation Modeling, 13, 497-519. doi:10.1207/s15328007sem1304_1

Murphy, P. R., \& Jackson, S. E. (1999). Managing work role performance: Challenges for twenty-first century organizations and their employees. In D. R. Ilgen \& E. D. Pulakos (Eds.). The changing nature of work performance (pp. 325-365). San Francisco: Jossey-Bass.

Niessen, C., Sonnentag, S., \& Sach, F. (2012). Thriving at work: A diary study. Journal of Organizational Behavior, 33, 468-487. doi:10.1002/job.763

Nissly, J. A., Mor Barak, M. E., \& Levin, A. (2005). Stress, social support, and workers' intentions to leave their jobs in public child welfare. Administration in Social Work, 29, 79-100. Retrieved from https://eur01.safelinks.protection. outlook.com/?url=https\%3A\%2F\%2Fdoi.org\%2F10.1300\%2FJ1 47v29n01_06\&amp;data $=02 \% 7 C 01 \% 7 C \% 7 C 74 d 7 a 4 b 2158 \mathrm{e} 4 \mathrm{aab} 3 \mathrm{fea} 08 \mathrm{~d}$ 70210b699\%7C84df9e7fe9f640afb435aaaaaaaaaaa\%7C1\%7C0\%7C6369 80143605289189\&amp;sdata $=$ dH60P1 etVQxetUPG3UecNiQm7nOO7R m\%2FH4Id8jNB\%2B9w\%3D\&amp;reserved =0

Novaes, V. P., Ferreira, M. C., \& Valentini, F. (2015). Evidências de validade da Escala de Flexibilidade Psicológica no Trabalho em amostras brasileiras. Psico, 46, 362-373. doi:10.15448/1980-8623.2015.3.18679 
Novaes, V. P., Ferreira, M. C., \& Valentini, F. (2018). Psychological flexibility as a moderator of the relationships between job demands and resources and occupational well-being. The Spanish Journal of Psychology, 21, 1-13. Retrieved from https://eur01.safelinks.protection.outlook.com/?url=https \%3A\%2F\%2Fdoi.org\%2F10.1017\%2Fsjp.2018.14\&amp;data=02\%7C01 \%7C\%7C74d7a4b2158e4aab3fea08d70210b699\%7C84df9e7fe9f640af b435aaaaaaaaaaa\%7C1\%7C0\%7C636980143605289189\&amp;sdata= OnnyzhCvmLcINpz8\%2FlCdWGCXdpPI5rwuPNeEDPF39g8\%3D\&amp; reserved $=0$

Ouweneel, E., Schaufeli, W. B., \& Le Blanc, P. M. (2013). Believe, and you will achieve: Changes over time in selfefficacy, engagement, and performance. Applied Psychology: Health and Well-Being, 5, 225-247. doi:10.1111/ aphw.12008

Paterson, T. A., Luthans, F., \& Jeung, W. (2014). Thriving at work: Impact of psychological capital and supervisor support. Journal of Organizational Behavior, 35, 434-446. doi:10.1002/job.1907

Podsakoff, P. M., MacKenzie, S. B., Paine, J. B., \& Bachrach, D. G. (2000). Organizational citizenship behaviors: A critical review of the theoretical and empirical literature and suggestions for future research. Journal of Management, 26, 513-563. doi:10.1177/014920630002600307

Podsakoff, P. M., MacKenzie, S. B., \& Podsakoff, N. P. (2012). Sources of method bias in social science research and recommendations on how to control it. Annual Review of Psychology, 63, 539-569. Retrieved from https://eur01. safelinks.protection.outlook.com/? url=https\%3A\%2F\%2Fdoi. org\%2F10.1146\%2Fannurev-psych-120710-100452\&amp;data=02\%7C01 \%7C\%7C74d7a4b2158e4aab3fea08d70210b699\%7C84df9e7fe9f640afb43 5aaaaaaaaaaа\%7C1\%7C0\%7C636980143605289189\&amp;sdata= A\%2Fk\%2B1L6wVGB0tvUF4wFXOkw8MWePD1oBmhuiSDo1308\%3D\& amp;reserved $=0$

Porath, C., Spreitzer, G., Gibson, C., \& Garnett, F. G. (2012). Thriving at work: Toward its measurement, construct validation, and theoretical refinement. Journal of Organizational Behavior, 33, 250-275. doi:10.1002/ job.756

Rigotti, T., Schyns, B., \& Mohr, G. (2008). A short version of the occupational self-efficacy scale: Structural and construct validity across five countries. Journal of Career Assessment, 16, 238-255. doi:10.1177/106907270 7305763

Schaufeli, W. B., \& Bakker, A. B. (2004). Job demands, job resources, and their relationship with burnout and engagement: A multi-sample study. Journal of Organizational Behavior, 25, 293-315. doi:10.1002/job.248 
Schaufeli, W. B., \& Taris, T. W. (2014). A critical review of the Job DemandsResources Model: Implications for improving work and health. In G. Bauer \& O. Hämmig (Eds.). Bridging occupational, organizational and public health (pp. 43-68). Dordrecht, The Netherlands: Springer.

Sia, S. K., \& Duari, P. (2018). Agentic work behaviour and thriving at work: Role of decision making authority. Benchmarking: An International Journal, 25, 3225-3237. doi:10.1108/BIJ-07-2017-0204

Spector, P. E. (2006). Method variance in organizational research: Truth or urban legend? Organizational Research Methods, 9, 221-232. Retrieved from https://eur01.safelinks.protection.outlook.com/?url=https\%3A\%2F\% 2Fdoi.org\%2F10.1177\%2F1094428105284955\&amp;data=02\%7C01\%7C \%7C74d7a4b2158e4aab3fea08d70210b699\%7C84df9e7fe9f640afb435aa aaaaaaaaa\%7C1\%7C0\%7C636980143605289189\&amp;sdata=MEsN1DI 3sK5BTyERhm7knx5FE0Lsz8uJTdMwq4aA74E\%3D\&amp;reserved=0

Spreitzer, G., Porath, C., \& Gibson, C. (2012). Toward human sustainability: How to enable more thriving at work. Organizational Dynamics, 41, 155-162. Retrieved from https://eur01.safelinks.protection.outlook.com/?url=https \%3A\%2F\%2Fdoi.org\%2F10.1016\%2Fj.orgdyn.2012.01.009\&amp;data= 02\%7C01\%7C\%7C74d7a4b2158e4aab3fea08d70210b699\%7C84df9e7fe 9f640afb435aaaaaaaaaaaa\%7C1\%7C0\%7C636980143605289189\&amp; sdata $=$ aorCpL1IJONIqV18Y1CP2X\%2BMegX55B53L1DqxBb8I6I\%3D\& amp;reserved $=0$

Spreitzer, G., Sutcliffe, K., Dutton, J., Sonenshein, S., \& Grant, A. M. (2005). A socially embedded model of thriving at work. Organization Science, 16, 537-549. doi:10.1287/orsc. 1050.0153

Tremblay, M. A., \& Messervey, D. (2011). The Job Demands-Resources model: Further evidence for the buffering effect of personal resources. South African Journal of Industrial Psychology, 37, 1-10. Retrieved from https://eur01.safelinks.protection.outlook.com/?url=https\%3A\%2F\%2F doi.org\%2F10.4102\%2Fsajip.v37i2.876\&amp;data =02\%7C01\%7C\%7C7 4d7a4b2158e4aab3fea08d70210b699\%7C84df9e7fe9f640afb435aaaaaaa aaaa\%7C1\%7C0\%7C636980143605299181\&amp;sdata=GQuzlabgc1M5 \%2BZ9TD3Tb3nh5RrsxS3CuDl483wI\%2Fs50\%3D\&amp;reserved =0

Tucker, M. K., Jimmieson, N. L., \& Oei, T. P. (2013). The relevance of shared experiences: A multi-level study of collective efficacy as a moderator of job control in the stressor-strain relationship. Work \& Stress, 27, 1-21. doi:10.10 80/02678373.2013.772356 
Tyler, T. R., \& Blader, S. L. (2000). Cooperation in groups: Procedural justice, social identity and behavioral engagement. Philadelphia: Psychology Press.

Volman, F. E., Bakker, A. B., \& Xanthopoulou, D. (2013). Recovery at home and performance at work: A diary study on self-family facilitation. European Journal of Work and Organizational Psychology, 22(2), 218-234. doi: 10.10 80/1359432X.2011.648375

Xanthopoulou, D., Bakker, A. B., Demerouti, E., \& Schaufeli, W. B. (2007). The role of personal resources in the job demands-resources model. International Journal of Stress Management, 14, 121-141. doi:10.1037/10725245.14.2.121

\section{AUTHOR NOTES}

Vladimir P. Novaes, Ph.D. by the Postgradute Program in Psychology, Salgado de Oliveira University (Universo); Maria C. Ferreira, Ph.D. by the Higher Institute of Research (Isop), Getulio Vargas Foundation (FGV); Helenides Mendonça, Ph.D. by the Institute of Psychology, Brasília University (UnB); Cláudio V. Torres, Ph.D. by the Department of Psychology, California School of Professional Psychology (CSPP).

Vladimir P. Novaes is now professor of the Law and Business graduation courses at Universus Veritas University Center (Univeritas); Maria C. Ferreira is now professor at the Postgradute Program in Psychology of Salgado de Oliveira University (Universo); Helenides Mendonça is now professor at the School of Social Sciences and Health of Pontifical Catholic University of Goiás (PUC Goiás); Cláudio V. Torres is now professor at the Institute of Psychology of Brasília University (UnB).

Correspondence concerning this article should be addressed to Vladimir P. Novaes, Rua Marechal Deodoro, 211, Bloco C, Centro, Niterói, Rio de Janeiro, Brasil, CEP 24030-060.

E-mail: vladimir_novaes@hotmail.com

\section{EDITORIAL BOARD}

Editors-in-chief

Janette Brunstein

Silvia Marcia Russi de Domênico

Associated Editor

Sônia Maria Guedes Gondim

Technical Support

Vitória Batista Santos Silva

\section{EDITORIAL PRODUCTION}

Publishing Coordination

Jéssica Dametta

Layout Designer

Emap

Editorial Intern

Paula Di Sessa Vavlis

Graphic Designer

Libro

Language Editor

Daniel de Almeida Leão 